\title{
Calculation of Stray Losses and Temperature Distribution in Power Transformer Using Coupled Electromagnetic-Thermal Field Analysis
}

\author{
Xiuke $\mathrm{Yan}^{1, \mathrm{a}}$, Xiangdong $\mathrm{YU}^{2, \mathrm{~b}}$, Min Shen ${ }^{3, c}$ \\ ${ }^{1}$ School of Electrical Engineering, Shenyang University of Technology, Shenyang, 110870, China \\ ${ }^{2}$ School of Electrical Engineering, Shenyang University of Technology, Shenyang, 110870, China \\ ${ }^{3}$ School of Electrical and Information Engineering, Jiangsu University, Jiangsu, 212013, China \\ bemail: 294873482@qq.com
}

Keywords: Electromagnetic-Thermal Coupling; Stray Losses; Temperature Distribution; Power Transformer

\begin{abstract}
In order to calculate stray losses and predict temperature distribution as accurately as possible in power transformer tank walls and other mental constructive parts, an analysis method of the electromagnetic-thermal coupling is presented. TEAM Problem 21 (P21-B, P21 $\left.{ }^{\mathrm{a}}-2, \mathrm{P} 21^{\mathrm{C}}-\mathrm{M} 1\right)$ are adopted to verify the validation of the stray losses calculation by MagNet FEM software, showing that the calculation results are in good agreement with measured results. Then, taking the material properties affected by temperature into consideration, the two-way coupling analysis method is used to the calculation of stray losses and temperature distribution in power transformer.
\end{abstract}

\section{Introduction}

In the design of large power transformers, it is very important to determine as accurately as possible the amount and space distribution of stray losses due to leakage of magnetic flux, occurring in the winding and other metal parts. Many researchers and transformer manufacturers have proposed different analysis methods to calculate and reduce the stray losses in flitch plates, frames, and tank walls for eliminating the local overheating and efficiency decreasing [1][2][3][4]. Most transformer manufacturers still use the semi-empirical formulae to calculate stray losses and predict the maximum temperature rise. However, these methods are too oversimplified so that the results are inaccurate, or based on empirical techniques with questionable validity.

Due to the complicated construction of power transformers, the stray losses in structural parts of power transformers, especially for the concentration regions of eddy current which are induced by leakage field, may cause local overheating. Most of the power transformers are strongly restricted by thermal regulation specifying hot-spot temperature inside the transformer tank [5]. Therefore, it is essential to predict those temperature rises accurately and take some measurements to reduce the eddy current losses and eliminate the hot spots.

Based on electromagnetic analytical formulation linked with thermal finite element method, Paper [6] proposed 3-D methodology for the heating hazard assessment on transformer covers. Taking account of the temperature dependence of the heat transfer coefficient and of the conductivity, the paper [7] established a strong coupling between the thermal and electromagnetic equations to calculate eddy loss and predict temperature distribution of bushing adapters in three-phase generator step up transformer.

In this paper, taking the material properties affected by temperature into consideration, the electromagnetic-thermal coupling analysis for the temperature rise prediction in power transformer structural parts is adopted. This strong coupling analysis method is able to improve the calculation accuracy and give important guiding suggestions for reducing eddy current losses and avoiding local overheating.

\section{Method Description and Simulation Model}

To determine stray losses, a full three-dimensional (3D) finite-element-method (FEM) analysis 
of the power transformer is required. The three-phase five column transformer simulation model of OSFPS9-360MVA/330GY is shown in Figure1. MagNet FEM software, which has a time-harmonic analysis modular, is used to calculate the stray losses by $T-\Omega$ method. This coupling analysis has two steps. Firstly, the stray losses of electromagnetic model should be calculated to obtain the heat source. Next, the thermal model is solved with the heat source obtained from electromagnetic analysis. Considering the material properties affected by temperature, such as: heat transfer coefficient, the conductivity and the curve of B-H or B-W, heat sources are recalculated according to flow chart of coupled method iteratively in Figure2.
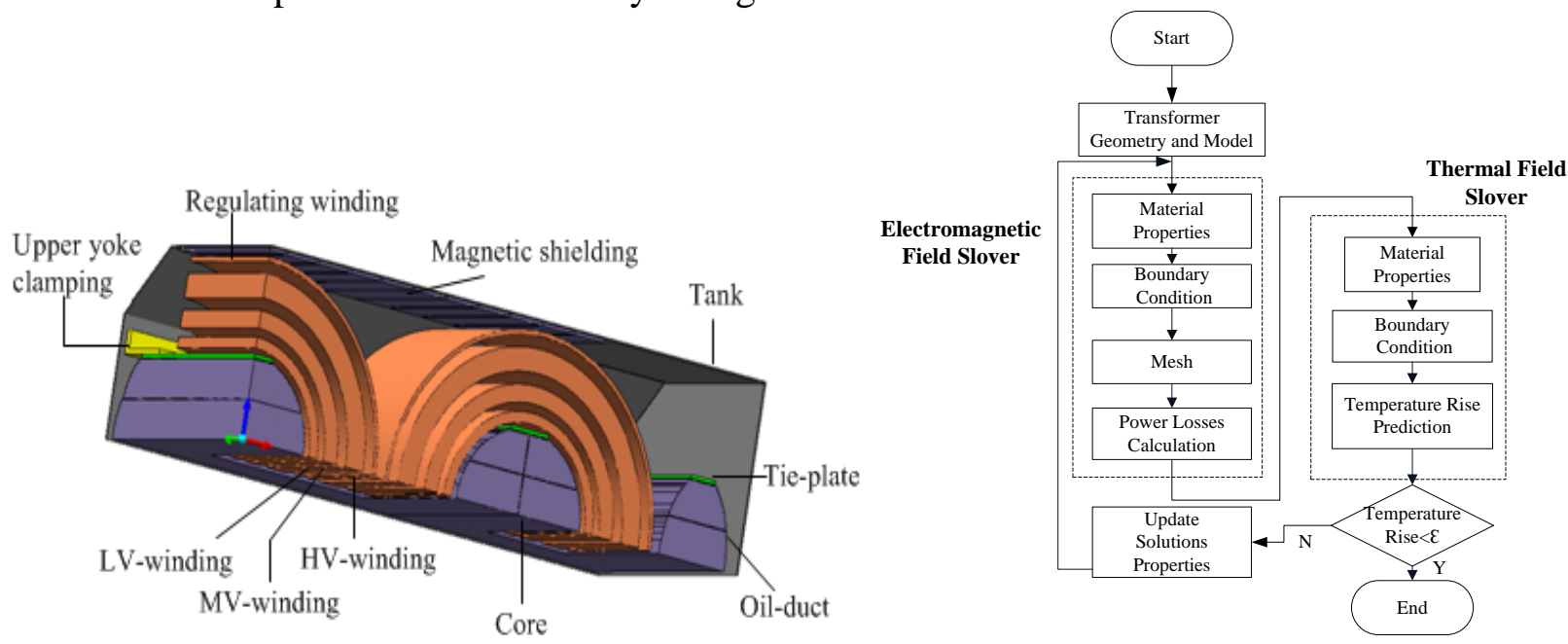

Fig.1. One-eighth of the simulation model

Fig.2. Flow chart of Electromagnetic-Thermal coupling field analysis

\section{Electromagnetic Analysis}

Considering the effect of displacement current, $T-\Omega$ method is adopted to calculating the stray losses in metal structural parts of power transformer.

$$
E=\left(\sigma+\varepsilon \frac{\partial}{\partial t}\right)^{-1} \nabla \times T
$$

Governing equation in eddy domains

$$
\nabla \times\left[\left(\sigma+\varepsilon \frac{\partial}{\partial t}\right)^{-1} \nabla \times T\right]+\mu \frac{\partial}{\partial t}[(T-\nabla \Omega)]=0
$$

According to $\nabla \cdot B=0$, we can get:

$$
\nabla \cdot[\mu(T-\nabla \Omega)]=0
$$

Governing equation in no eddy region include iron core, non-conductive parts and current source region

$$
\nabla \cdot\left[\mu\left(H_{s}-\nabla \Omega\right)\right]=0
$$

The stray losses in metal structure parts of power transformer include eddy current loss $\mathrm{P}_{e}$ and hysteresis loss $\mathrm{P}_{h}$. The calculation of eddy current loss and hysteresis loss are respectively shown as equation (5) and (6).

$$
P_{e}=\int \frac{\overline{J \cdot J}}{\sigma} d V=\int \frac{J_{0 r m s} \cdot J_{0 r m s}^{*}}{\sigma} d V
$$

$\mathrm{J}$ represents current density and $\mathrm{J}_{0}$ is vector, related to $\mathrm{J}$. $\sigma$ is electrical conductivity of metal parts. Owing to the hysteresis loss $W_{h}$ is treated to be as a function of the peak value of the flux density $B_{m}[9]$, the hysteresis loss will be calculated by: 


$$
P_{h}=W_{h}=\sum_{i=1}^{N(i)} W_{h}^{(i)}\left(B_{m}^{(i)}\right) \rho V(i)
$$

$W_{h}^{(i)}$ denotes the dc hysteresis loss (W/kg), $B_{m}^{(i)}$ is the peak value of the flux density, $\rho$ is the density of the steel plate, $V(i)$ is the volume of an element, and $N(i)$ is the total number of elements.

$$
P=P_{h}+P_{e}
$$

A. Verified with TEAM Problem 21 (P21-B, P21 $\left.{ }^{\mathrm{a}}-2, \mathrm{P} 21^{\mathrm{C}}-\mathrm{M} 1\right)$

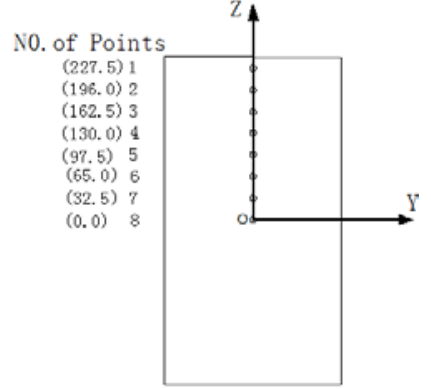

(a) The Front view

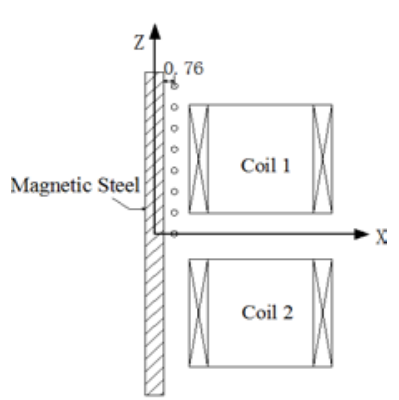

(b) The Left view

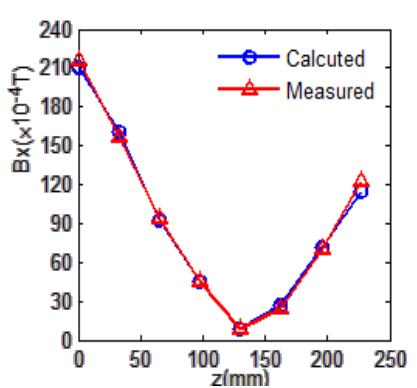

(c) The curve graphs of $\mathrm{B}_{x}$

Fig.3. Compare the value of measured $\mathrm{B}_{x}$ with the calculated in specific locations in P21-B model And other results of Team Problem 21 models are listed in Table I:

TABLE I

\begin{tabular}{|c|c|c|c|c|c|}
\hline Model & $\begin{array}{l}\text { Measured } \\
\text { results }{ }^{[8]}\end{array}$ & $\begin{array}{l}\text { Calculated } \\
\text { Total Losses }\end{array}$ & $\begin{array}{l}\text { Eddy Loss } \\
\end{array}$ & $\begin{array}{l}\text { Hysteresis } \\
\text { Loss }\end{array}$ & $\begin{array}{l}\text { Relative } \\
\text { Error (\%) }\end{array}$ \\
\hline P21-B & 11.97 & 11.84 & 7.64 & 4.2 & $1.08 \%$ \\
\hline $\mathrm{P} 21^{\mathrm{a}}-2$ & 1.68 & 1.71 & 1.71 & --- & $1.79 \%$ \\
\hline $\mathrm{P} 21^{\mathrm{C}}-\mathrm{M} 1$ & 3.72 & 3.80 & 1.05 & 2.75 & $2.15 \%$ \\
\hline
\end{tabular}

COMPARISON OF COMPUTATION RESULT OF STRAY LOSS IN TEAM PROBLEM 21 (UNIT: W)

\section{B. The Results and Analysis of Simulation Model}

In Figure 4 we know that magnetic shielding on tank walls may absorb the leakage magnetic flux, and change the route of leakage flux. Compared with tank walls without magnetic shielding in Figure4(a), the maximum flux density decrease 0.05T in Figure4(b). Eddy current density distribution in tank walls is more uniform in Figure5 (b) than in (a), but, the magnetic shielding may cause other hot spots in mental parts.

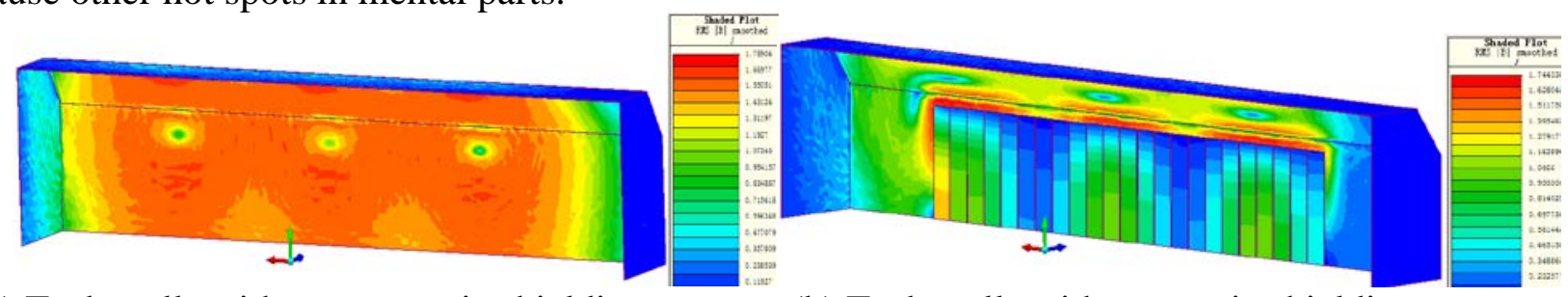

(a) Tank walls without magnetic shielding

(b) Tank walls with magnetic shielding

Fig.4.The magnetic flux density distribution of the tank walls

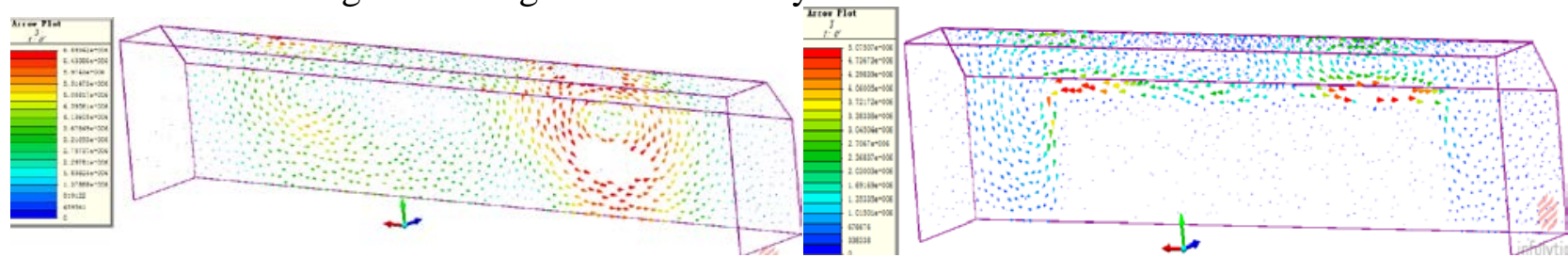

(a) Tank walls without magnetic shielding

(b) Tank walls with magnetic shielding

Fig.5.The arrow plot of eddy current density distribution of the tank walls

In order to block the concentration of eddy current and eliminate hot spots in tie-plate, slotting is adopted in Figure 6. The concrete results are listed in Table II. 


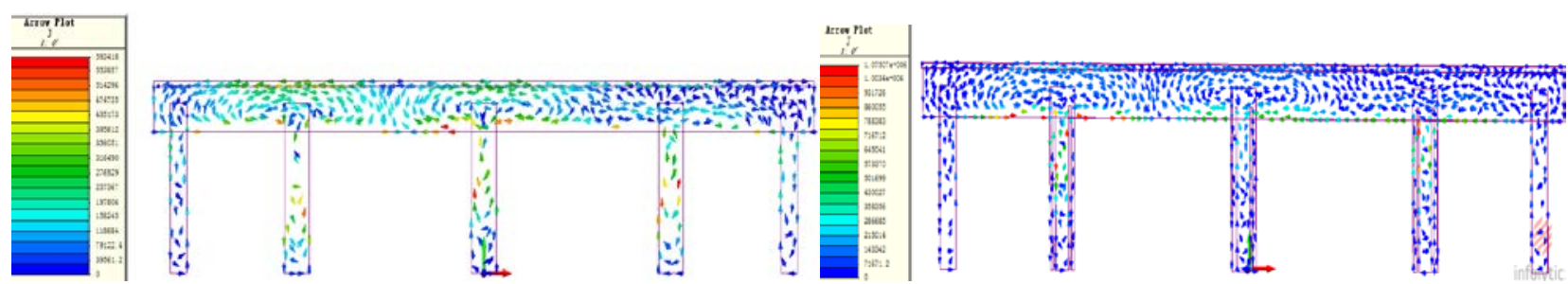

Fig.6.The arrow plot eddy current density distribution of the tie-plate and yoke clamping

TABLE II

COMPARISON OF COMPUTATION RESULT IN SIMULATION MODEL

\begin{tabular}{c|c|c|c|c|c|c}
\hline \hline \multirow{2}{*}{ Mental structure parts } & \multicolumn{2}{|c|}{ Tank walls } & \multicolumn{2}{c|}{ Yoke Clamp } & \multicolumn{2}{c}{ Tie-plate } \\
\cline { 2 - 7 } & $\begin{array}{c}\text { Without } \\
\text { magnetic } \\
\text { shielding }\end{array}$ & $\begin{array}{c}\text { With } \\
\text { magnetic } \\
\text { shielding }\end{array}$ & $\begin{array}{c}\text { Without } \\
\text { magnetic } \\
\text { shielding }\end{array}$ & $\begin{array}{c}\text { With } \\
\text { magnetic } \\
\text { shielding }\end{array}$ & $\begin{array}{c}\text { No } \\
\text { slot }\end{array}$ & $\begin{array}{c}\text { Two } \\
\text { slots }\end{array}$ \\
\cline { 2 - 8 } Loss density/(W/m $\left.{ }^{3}\right)$ & $8.9 \times 10^{6}$ & $3.7 \times 10^{6}$ & $1.4 \times 10^{6}$ & $1.2 \times 10^{6}$ & $1.9 \times 10^{6}$ & $1.5 \times 10^{6}$ \\
Eddy current loss/(KW) & 110.8 & 80.58 & 33 & 14.336 & 7.62 & 4.776 \\
Hysteresis loss/(KW) & 19.2 & 3.456 & -- & -- & -- & -- \\
Stray losses /(KW) & 130 & 83.514 & 33 & 14.336 & 7.62 & 4.776 \\
\hline \hline
\end{tabular}

\section{Thermal Analysis}

According to the theories of heat transfer, heat transfer process are carried out by heat conduction(referred to as thermal conductivity), convection heat transfer and radiation heat transfer heat exchanger three basic forms of complex formed [10]. The heat source can be obtained from electromagnetic analysis by MagNet FEM software, which would be coupled with ThermNet FEM analysis as follows.

A. Governing equation:

$$
\nabla \cdot k \nabla T=-Q+\rho c \frac{\partial T}{\partial t}
$$

Where $\mathrm{k}$ is the thermal conductivity, $Q$ is the heat flux density $\left(\mathrm{W} / \mathrm{m}^{3}\right), \rho$ is the density $\left(\mathrm{kg} / \mathrm{m}^{3}\right), c$ is heat capacity $\left(\mathrm{W} / \mathrm{m}^{\circ} \mathrm{C}\right), T$ is the specific temperature $\left({ }^{\circ} \mathrm{C}\right)$ for boundary condition.

$$
-(k \nabla T) \cdot n=q+q_{c}+q_{r}
$$

And $q$ is the heat flux flow out of the system, $q_{c}$ and $q_{r}$ are the heat flux produced by convection heat transfer and radiation heat transfer, respectively.

$$
\begin{aligned}
& q_{c}=h_{c}(T)\left(T-T_{e}\right) \\
& q_{r}=h_{r}(T)\left(T^{4}-T_{e}^{4}\right)
\end{aligned}
$$

Where $h_{c}(T)$ is the convection heat exchange coefficient; $h_{r}(T)$ is the radiation heat exchange coefficient; $\mathrm{T}_{e}$ is the ambient temperature.

B. Heat Transfer Coefficient

$$
\begin{aligned}
& h=\frac{k}{\delta} N u \\
& N u_{v}=\left\{0.825+\frac{0.387 R a^{1 / 6}}{\left[1+\left(\frac{0.492}{P r}\right)^{9 / 16}\right]^{8 / 27}}\right\}^{2} \\
& N u_{h}=0.27 R a^{1 / 4}
\end{aligned}
$$


Where $\mathrm{h}$ is heat transfer coefficient and $\delta$ is characteristic length(m). Respectively, $\mathrm{Nu}_{\mathrm{v}}$ and $\mathrm{Nu}_{\mathrm{h}}$ are Nusselt number of vertical plane and Nusselt number of horizontal plane, and $\mathrm{Ra}$ and $\mathrm{Pr}$ represent Rayleigh number and Pandtl number, respectively [5].

C. Temperature distribution in the structural parts

The predicted temperature distribution on the surface of mental parts in the power transformer by the coupled analysis method is shown in Figure7, which shows that hot-spot temperature rising up to $116.3^{\circ} \mathrm{C}$, The specific ambient temperature is $25^{\circ} \mathrm{C}$, and the temperature rise is near $91 \mathrm{~K}$. Therefore, it is essential to take some measurements to lower the maximum temperature rise. As seen in Figure 8, slotting on the tie-plate enable the highest temperature below $100^{\circ} \mathrm{C}$ in the yoke clamp and tie-plates.

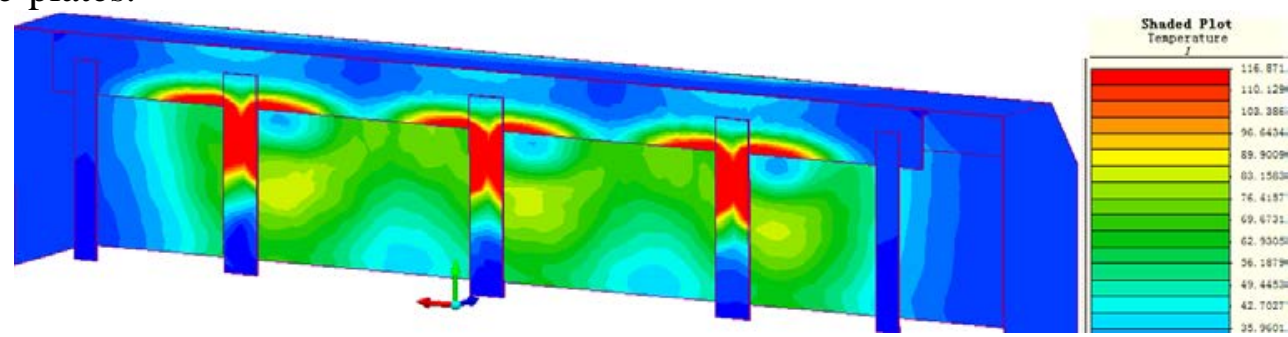

Fig.7. Temperature distribution in the mental structural parts of transformer
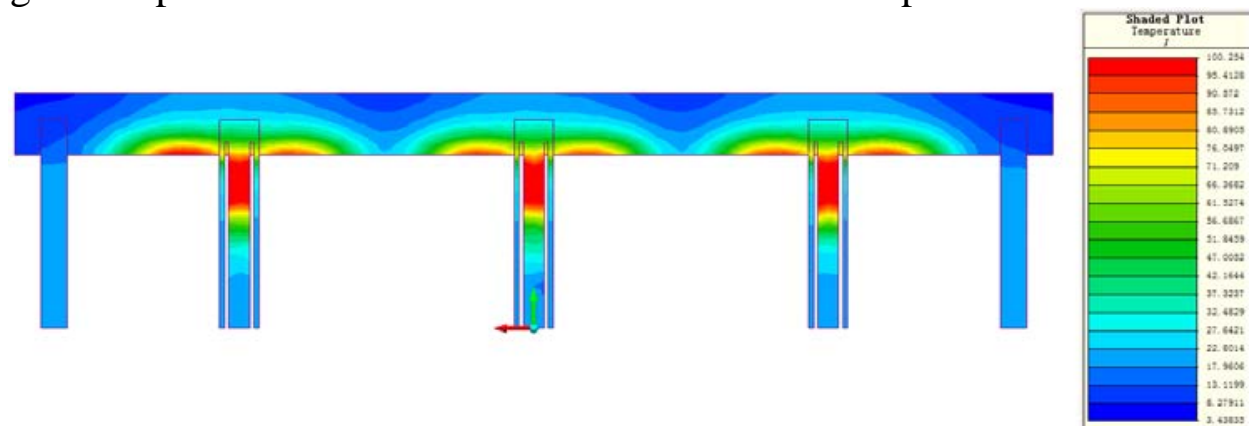

Fig.8.Temperature distribution in the yoke clamp and tie-plate with two slotting

The temperature distribution of the outside surface of tank walls reached $98^{\circ} \mathrm{C}$, it may cause overheating hazard during the operation, shown in Figure 9(a). From the Figure 9(b), we can see the highest temperature rise lower to $59.8^{\circ} \mathrm{C}$, when the magnetic shielding is adopted.
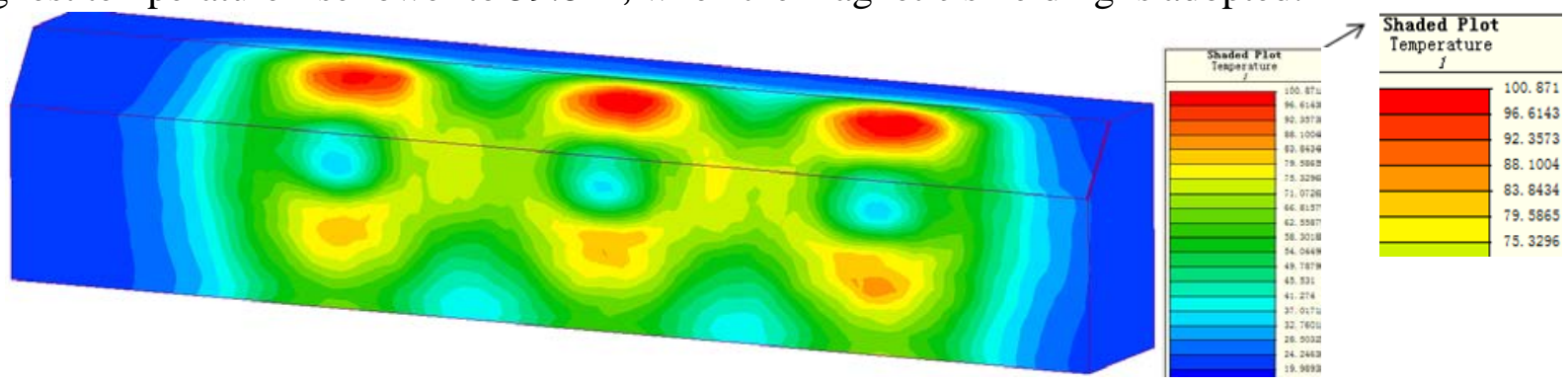

(a)Tank walls without magnetic shielding

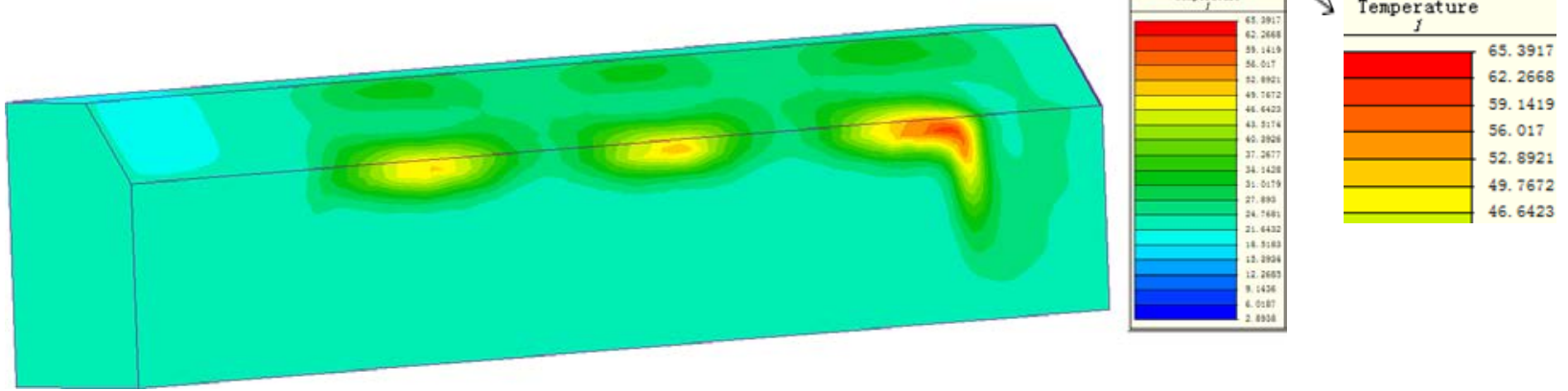

(b) Tank walls with magnetic shielding

Fig.9. Temperature distribution in the outside surface of transformer 


\section{Conclusion}

Based on the two-way electromagnetic-thermal coupling analysis method, the total stray losses in structural parts of power transformer are calculated as heat source. Considering the conductivity and heat transfer coefficient affected by temperature, the calculation of stray losses and temperature rise distribution in power transformer mental parts are more accurate. Tank walls with magnetic shielding and slotting on the tie plate can reduce stray losses significantly and eliminate hot spots. Therefore, the proposed method is considered to be available and could be adopted in the thermal design of power transformers.

\section{Acknowledgement}

This work was supported by Shenyang Power Transformers of TBEA CO., LTD.

\section{References}

[1] Lenart Kralj, Damijan Miljavec, Stray losses in power transformer tank walls and construction parts, XIX International Conference on Electrical Machines - ICEM 2010, Rome.

[2] Livio Susnjic, Zijad Haznadar, Zvonimir Valkovic, 3D finite-element determination of stray losses in power transformer [J], Electric Power Systems Research.2008:78, 1814-1818.

[3] Maxym V. Ostrenko, Olexandr L. Tarchutkin, Bogdan Y. Andriienko, Power Transformers and Reactors Stray Losses and Temperatures Calculation Using Coupled IEM and FEM Technique, IEEE Region 8 SIBIRCON-2010. Irkutsk Listvyanka, Russia, 2010:717-721.

[4] S.V. Kulkarni, J.C. Olivares, R. Escarela-Perez, V.K. Lakhiani and J. Turowski. Evaluation of eddy current losses in the cover plates of distribution transformers [J]. IEE Proc.-Sci. Meas.Technol. 2004: 151(5).

[5] Hyun-Mo Ahn, Byuk-Jin Lee, and Sung-Chin Hahn, An Efficient Investigation of Coupled Electromagnetic-Thermal-Fluid Numerical Model for Temperature Rise Prediction of Power Transformer, International Conference on Electrical Machines and Systems(ICEMS),Beijing, 2011,1-4.

[6] Xose M. López-Fernández, Patricia Penabad-Durán and Janusz Turowski. 3-D Methodology for the Heating Hazard Assessment on Transformer Covers. XIX International Conference on Electrical Machines - ICEM 2010, Rome.

[7] Kurt Preis, Oszkár Bíró, Gerhard Buchgraber, and Igor Ticar. Thermal-Electromagnetic Coupling in the Finite-Element Simulation of Power Transformers [J]. IEEE TRANSACTIONS ON MAGNETICS. 2006:42(4).

[8] Z. Cheng, R.Hao, Norio Takahashi. Engineering-Oriented Benchmarking of Problem 21 Family and Experimental Verificationp [J]. IEEE Trans. on Magn. 2004:40( 2):1394-1397.

[9] Zhiguang Cheng, Norio Takahashi, Sumei Yang. Loss Spectrum and Electromagnetic Behavior of Problem 21 Family [J]. IEEE TRANSACTIONS ON MAGNETICS. 2006:42(4).

[10] Cheng Zhiguang, Norio Takahashi, Behzad Forghani. Electromagnetic and Thermal Field Modeling and Application in Electrical Engineering [M]. Beijing: Science Press, 2009. 344-351. 